\title{
IMPLEMENTASI MAQASID SYARIAH PADA ANNUAL REPORT BANK UMUM SYARIAH SEBAGAI MITRA UNIVERSITAS ISLAMI (STUDI KASUS PADA BANK SYARIAH MANDIRI)
}

\author{
Frisztina Anisa ${ }^{1^{*}}$, Veni Soraya Dewi ${ }^{2}$, Ade Vira Agustina ${ }^{3}$ \\ 1,3Prodi Akuntansi/FEB, Universitas Muhammadiya Magelang \\ ${ }^{2}$ Prodi Manajemen/FEB, Universitas Muhammadiyah Magelang \\ E-Mail: friztinanisa@ummgl.ac.id, venisorayadewi@ummagelang.ac.id
}

\begin{abstract}
Islam has arranged all matters relating to human life in the world, including economic activities. In carrying out economic activities must be in accordance with the purpose of life of a Muslim with its implementation is mashlahah on the activities of maqasid syaria. Maqashid sharia has five factors, namely guarding religion, guarding the soul, guarding reason, guarding offspring, and protecting property. Sharia Commercial Bank as a supporter of the community's economy in carrying out all its activities must be based on sharia provisions. Annual Report reflects the activities of Sharia Commercial Banks both financial and non-financial. Maqasid Sharia as an indicator of the implementation of sharia principles must be reflected in the Sharia Commercial Bank Annual Report. This study aims to determine the implementation of the Maqasid Syaria in the Sharia Commercial Bank annual report. The sample in this study is Bank Syariah Mandiri Annual Report. The research method used in this study is qualitative research that is descriptive research and analysis based on theories and other supporting sources. The results of the study are Bank Syariah Mandiri has implemented all aspects of the maqasid syaria as reflected in the Annual Report.
\end{abstract}

Keywords: Sharia Enterprise Theory, Maqasid Syaria, Sharia Commercial Banks

Abstrak: Islam sudah mengatur segala urusan yang berkaitan dengan kehidupan manusia di dunia, termasuk aktifitas ekonomi. Dalam melakukan aktivitas ekonomi harus sesuai dengan tujuan hidup seorang muslim dengan implementasinya adalah mashlahah pada aktivitas maqasid syariah. Maqashid syariah memiliki lima faktor, yaitu menjaga agama, menjaga jiwa, menjaga akal, menjaga keturunan, dan menjaga harta. Bank Umum Syariah sebagai salah satu pendukung perekonomian masyarakat dalam menjalankan segala aktivitasnya harus berdasarkan ketentuan syariah. Annual Report mencerminkan dari aktifitas Bank Umum Syariah baik keuangan maupun non keuangan. Maqasid Syariah sebagai indikator terlaksananya prinsip syariah harus tercermin dalam Annual Report Bank Umum Syariah. Penelitian ini bertujuan untuk mengetahui implementasi maqasid syariah pada annual report Bank Umum Syariah. Sampel pada penelitian ini adalah Annual Report Bank Syariah Mandiri. Metode penelitian yang dipakai dalam penelitian ini adalah penelitian kualitatif yaitu penelitian yang bersifat deskriptif dan analisis berdasarkan teori dan sumber-sumber lain yang mendukung. Hasil dari penelitian adalah Bank Syariah Mandiri telah mengimlementasikan seluruh aspek maqasid syariah yang tercermin pada Annual Report.

Kata kunci: Syaria enterprise theory, maqasid syariah, Bank Umum Syariah 


\section{PENDAHULUAN}

Persaingan ekonomi dan bisnis di Indonesia sudah semakin pesat. Lembagalembaga keuangan bermunculan menawarkan kelebihannya masingmasing, baik yang berbasis konvensional maupun syariah. Keberadaan Lembaga Keuangan Syariah dalam bidang perbankan, asuransi, pasar modal, pegadaian, dll menjadi daya tarik tersendiri bagi masyarakat Indonesia yang mulai sadar akan pentingnya hukum Islam dalam pengelolaan keuangannya. Dalam rangka memertahankan kredibilitasnya di mata investor dan publik, Bank Umum Syariah (BUS) seharusnya mampu menunjukkan bukti bahwa mereka bisa dipercaya. Bukti tersebut dapat kita lihat pada kinerja BUS yang tercermin dalam laporan keuangannya. Kepercayaan dan loyalitas pemilik dana terhadap bank merupakan faktor yang sangat penting dan mempermudah manajemen bank untuk menyusun strategi bisnis yang baik.

Perkembangan lembaga keuangan Syariah didasarkan pada aturan UndangUndang No. 21 tentang Perbankan Syariah tahun 2008. Undang-Undang ini menjadi payung hukum serta bukti pengakuan akan kehadiran perbankan syariah di Indonesia. Berdasarkan data sampai pada bulan Januari tahun 2018 berjumlah 13 Bank Umum Syariah dan 21 Unit Usaha Syariah serta 167 Bank Perkreditan Rakyat Syariah [1].

Berbeda dengan perbankan konvensioanal yang profit oriended, BUS dalam menjalankan kegiatan operasionalnya harus berdasarkan nilai-nilai syariah. Perbankan Syariah merupakan perbankan yang sesuai dengan prinsip dan sistem nilai Islam yang telah diatur dan ditetapkan dalam Syariat Islam [2]. Setiap transaksi keuangan Islam harus bebas dari bunga, judi dan gharar [3]. Berdasarkan hal tersebut, tujuan BUS hendaknya diturunkan dari tujuan hidup seorang muslim yaitu fallah (kesuksesan dunia dan akhirat) dengan implementasinya adalah mashlahah pada aktivitas maqasid syariah. Dalam konteks dan perspektif Islam, mashlahah berarti apa yang baik bermanfaat di mata syariah [4].

Maqasid syariah merupakan tujuan Allah dan Rosul-Nya dalam merumuskan hukum-hukum Islam [5]. Pendapat lain mendefinisikan maqasid syariah sebagai maksud atau tujuan yang disyariatkan hukum Islam [6]. Tujuan tersebut dapat ditelusuri dalam ayat-ayat Al Quran dan Hadist sebagai alasan logis bagi rumusan suatu hukum yang berorientasi pada kemaslahatan umat manusia. Konsep maqasid syariah bertujuan untuk mewujudkan kemaslahatan di dunia dan akhirat. Konsep ini mengandung keadilan, rahmat, kemaslahatan, dan juga hikmah bagi seluruh umat manusia. Maqashid syariah memiliki lima faktor, yaitu pencapaian agama, meningkatkan kualitas hidup, meningkatkan kualitas ilmu, meningkatkan kualitas keturunan, dan meningkatkan kuantitas harta. Kelima hal tersebut yang membedakan organisasi Islam dengan organisasi nasional lainnya.[7]

Shariah enterprise theory merupakan enterprise theory yang telah diinternalisasi dengan nilai-nilai Islam guna menghasilkan teori yang transcendental dan lebih humanis [8]. Artinya teori yang mengakui adanya pertanggungjawaban tidak hanya kepada pemilik perusahaan saja melainkan kepada kelompok stakeholders yang lebih luas.

PT. Bank Syariah Mandiri (BSM) yang berdiri tahun 1999 adalah salah satu BUS yang sampai sekarang mendapatkan kepercayaan masyarakat terbukti dari kinerjanya yang cukup stabil dan bertambahnya produk-produk syariah yang ditawarkan. Kepercayaan masyarakat pada BSM tentu saja tidak hanya dari segi finansial saja, namun 
juga bagaimana BSM melandaskan segala aktifitasnya pada hukumhukum syariah. Pada tahun 2017, Universitas Muhammadiyah Magelang sebagai Universitas Islami berdasarkan indikator maqasid syariah [9] bermitra dengan BSM dalam sistem pengganjian karyawannya. Hal ini dilakukan karena sebagai Universitas yang berlandaskan Islam hendaknya segala sesuatu harus berdasarkan hukum Islam termasuk pengelolaan keuangannya. Selain itu, dalam rangka membiasakan dan upaya mengajak seluruh karyawannya untuk beralih dari bank konvensional ke BUS. Pemilihan BSM pastinya sudah berdasarkan berbagai pertimbangan baik dari segi kesehatan bank maupun sistem operasionalnya.

BSM sendiri sebagai BUS hendaknya memasukkan indikator maqasid syariah dalam setiap aktifitasnya dan hal ini tercermin dalam laporan keuangannya terlebih dalam annual report. Annual Report adalah alat komunikasi antara perusahaan dan stakeholder yang dapat digunakan sebagai bahan pertimbangan dalam pengambilan keputusan. Dalam annual report disajikan kegiatan-kegiatan yang dilakukan perusahaan baik segi keuangan maupun non keuangan.

Penelitian ini bertujuan untuk mengetahui implementasi maqasid syariah pada annual report Bank Umum Syariah sebagai mitra Universitas yang Islami.[10]

\section{METODE PENELITIAN}

Jenis penelitian ini adalah penelitian kualitatif yaitu penelitian yang bersifat deskriptif dan cenderung menggunakan analisis. Penelitian kualitatif bertujuan untuk menjelaskan fenomena dengan sedalam-dalamnya melalui pengumpulan data sedalam-dalamnya [11].

Sampel dan Teknik Penyampelan. Sampel dari penelitian ini adalah annual report Bank Syariah Mandiri tahun 20162018.
Data dan Sumber Data. Data yang digunakan yaitu data sekunder yang diperoleh dari studi literatur. Analisis data melalui observasi dan data pendukung yang diperoleh, peneliti akan membuat rangkuman dan menganalis masing-masing poin maqasid, sehingga akan diperoleh jawaban dan kesimpulan tentang tujuan dari penelitian ini. Indikator observasi terkait maqasid yaitu meliputi perlindungan terhadap agama (al-Dien), perlindungan terhadap jiwa (al-Nafs), perlindungan terhadap akal (al$A q l)$, perlindungan terhadap kehormatan dan keturunan (Hifdz An-Nasb), serta perlindungan terhadap harta (al-Maal) menurut Syatibi dalam [12], [5] dan [13]. Selain itu, peneliti akan menelaah sumber-sumber dan kajian literatur dari Al Quran, Hadist dan literatur lain yang mendukung.[14]

\section{HASIL DAN PEMBAHASAN \\ Implementasi Perlindungan terhadap Agama (al-Dien)}

Kebutuhan pokok adalah kebutuhan yang wajib terpenuhi atau dalam maqasid syariah disebut kebutuhan dharuriyat. Apabila padatingkataninitidakterpenuhi, maka terancamlah keselamatan umat manusia di dunia maupun di akhirat. Agama adalah kebutuhan pokok yang harus dimiliki setiap manusia. Agama digunakan sebagai landasan hidup manusia dalam bertindak dan berbuat sesuatu. Artinya dengan agama manusia akan bertindak sesuai tuntunan agama dan tidak melanggar apa yang menjadi tuntunan dalam agama, sehingga manusia akan memiliki kepatuhan dan ketaatan sesuai dengan konsep yang ada pada sebuah agama.[15]

Allah SWT telah menurunkan agama yang sebagai pedoman hidup yaitu Islam. Agama Islam diturunkan sebagai agama yang sempurna, mengajarkan bagaimana manusia harus bertindak sebagai makhluk Allah (hablumminallah) maupun sebagai 
makhluk sosial (hablumminna nas), dan menyeimbangkan kehidupan dunia dan akhirat. Seperti dikutip dalam Al Quran sebagai berikut:

Sesungguhnya agama (yang diridhai) disisi Allah hanyalah Islam.... (QS. Ali Imron: 19)

... Pada hari ini telah Aku sempurnakan untukmu agamamu, dan telah Aku cukupkan kepadamu nikmat-Ku, dan telah Aku ridhai Islam sebagai agama bagimu ... (QS. Al-Maa-idah: 3)

Bentuk memelihara agama pada BSM dibuktikan dengan: Pertama, adanya Dewan Pengawas Syariah (DPS) yang bertugas untuk mengawasi seluruh aktifitas di BUS agar tetap sesuai dengan prinsip-prinsip Syariah yang berlandaskan Al quran dan Hadits. Fokus pemeriksaan DPS BSM terhadap pemenuhan aspek-aspek sharia compliance meliputi kesesuaian akad dalam transaksi, terpenuhinya unsur-unsur saat akad, dll. Dengan adanya DPS dan Dewan Pengawas Nasional membuat keabsahan BSM semakin terjamin dan insyaAllah dapat dipercaya oleh masyarakat. Kedua, dalam beberapa kegiatan Corporate Social Responsibility (CSR) nya, BSM konsisten membantu untuk pembangunan sarana ibadah, kegiatan dakwah, dan keagamaan lainnya.

Ketiga, memberikan ijin kepada setiap karyawan untuk menjalankan ibadahnya (sholat, puasa), baik yang wajib maupun sunnah (haji dan umrah).

Keempat, penerapan konsep menjaga agama yang diterapkan bertujuan agar setiap manusia tidak kehilanganjatidirinya sebagai seorang muslim. Penerapan konsep ini bisa dilihat dari perilaku dan pakaian karyawannya, misalnya bagi karyawati wajib menggunakan hijab dan berpakaian sesuai dengan syariat Islam.
Dengan begitu karakter dan ciri khas orang Islam akan terlihat.

\section{Implementasi Perlindungan Jiwa $(A n-N a f s)$}

Kebutuhan dharuriyat dilakukan dengan meningkatkan kualitas hidup yaitu menjaga jiwa sebagai alasan diwajibkannya meningkatkan kualitas Sumber Daya Insani (SDI) salah satunya dengan menjaga kualitas ilmu [16]. Manusia sebagai SDI merupakan aset yang utama yang berfungsi sebagai pemimpin dan pelaksana dari jalannya semua proses yang ada di dalamnya. Untuk itu, agar pemimpin, pelaksana, dan seluruh stakeholder yang ada dapat menjalankan fungsinya dengan baik dan hasilnya maksimal maka kualitas SDI harus ditingkatkan. Jika peningkatan kualitas SDI diabaikan maka BUS tidak akan berkembang dan lambat laun akan tertinggal.

Peningkatan kualitas SDI ditempuh dengan cara: Pertama, memastikan ketersediaan sumber daya yang berkualitas pada saat yang tepat melalui proses perekrutan. Penambhan karyawan BSM dilakukan seiring dengan ekspansi jaringan. Kedua, menempatkan SDI dalam lingkungan kerja yang baik, melakukan coaching dan supervisi sebelum beraktifitas, memperkuat basic knowledge perbankan Syariah bagi karyawan, adanya program talent management, mengembangkan career path pegawai, melakukan rotasi dan mutasi, reward dan punishment yang tepat sehingga menjadi motivasi karyawan.

Ketiga, bukti bahwa BSM peduli terhadap karyawannya dalam bidang kesehatan adalah dengan mengikutsertakan karyawannya dalam Asuransi Jiwa Inhealth Indonesia (Mandiri Inhealth) dan BPJS Kesehatan yang menjamin rawat inap maupun rawat jalan, general check up, dan pengobatan keluar negeri. 
Keempat, secara psikologis dan sosiologis penggunaan akad-akad antar pihak menuntun manusia untuk saling menghargai dan menjaga amanah. Kelima, karyawan dituntut untuk berperilaku, berpakaian, dan berkomunikasi secara sopan dan Islami kepada nasabah.

Keenam, untuk menjamin terpeliharanyahak hidup secara terhormat dan memelihara jiwa BSM memberikan kebebasan berkarya, kebebasan berfikir dan mengeluarkan pendapat, serta kebebasan bertempat tinggal dimanapun ditengah dinamika sosial sepanjang tidak merugikan orang lain. Sistem penggajian yang pasti dan pemberian dana pensiun bagi karyawan setelah masa baktinya selesai. Hal ini sesuai dengan prinsip Islam dalam hal memelihara jiwa dari segi finansial.

Berdasarkan hal-hal tersebut di atas, dapat disimpulkan bahwa dalam memelihara jiwa, BSM senantiasa mewujudkan peningkatan kualitas Sumber Daya Insani (SDI) serta pemenuhan kebutuhan pokok untuk hidup (sandang, pangan dan papan). Artinya kebutuhan akan pangan, sandang dan papan adalah mutlak harus terpenuhi untuk menjaga jiwa dan akal manusia, agar dapat menjaga eksistensi hidup serta menjalankan fungsi utamanya sebagai pelaku utama pembangunan (khalifah) [17].

\section{Implementasi Perlindungan Akal (Al- Aql)}

Kebutuhan dharuriyat berikutnya yaitu menjaga akal manusia. Konsep disini diartikan bahwa manusia diwajibkan untuk menjaga akal baik secara fisik mau psikis. Artinya manusia menjaga secara fisik dengan mengkonsumsi makanan yang halal dan baik, misalnya tidak mengkonsumsi minuman keras, narkoba dan memakan sesuai sesuai porsi dan kebutuhan (tidak berlebihan) dan tidak mubadzir, serta berolahraga.[10]
Sedangkan menjaga akal secara psikis, dilakukan dengan cara menuntut ilmu baik secara formal, informal maupun nonformal.

Cara pertama, Dewan Komisaris secara berkelanjutan meminta dan mengingatkan Direksi untuk melakukan peningkatan integritas dan kompetensi karyawan melalui pelatihan-pelatihan yangbisamendukungnyadalam pekerjaan maupun dirinya sendiri. Pembelajaran secara e-learning terus dikembangkan melalui penambahan modul berbasis macromedia sebanyak 25 modul pada 2014. Kedua, BSM juga memberikan beasiswa kepada siswa-siswa yang kurang mampu agar dapat meneruskan pendidikannya, adanya bantuan dalam pembangunan maupun renovasi sekolah dan pesantren, serta memberikan fasilitas pendidikan yang lain baik bagi karyawan maupun masyarakat sekitar.

Ketiga, untuk mendukung proses penyebaran pengetahuan secara menyeluruh, BSM mengimplementasikan Knowledge Management (KM) sejak tahun 2012. Tujuannya adalah menjadikan BSM sebagai bank Syariah berbasis pengetahuan yang inovatif.

Keempat, meningkatkan pemahaman praktek perbankan Syariah yang dilakukan DPS. DPS memberikan arahan dan penguatan materi akad dan produk perbankan Syariah kepada staf cabang, mengadakan Forum Klinik Syariah untuk menjawab keluhan sekaligus menerima masukan yang dapat memperbaiki kualitas pemenuhan aspek Syariah. Indikator pemeliharaan akal terdiri dari pendidikan, penerangan dan kebudayaan, dan penelitian ilmiah [18].

\section{Implementasi Perlindungan Keturunan (Hifdz An-Nasb)}

Keturunan bisa diartikan sebagai kesinambungan. Keturunan harus dipelihara sebaik-baiknya karena menentukan kualitas kehidupan di masa 
yang akan datang. Mendidik keturunan dengan dasar agama merupakan bekal bagi orang tuanya karena doa anak yang sholeh adalah salah satu amal jariah yang tidak akan terputus.

Keturunan yang sholeh dan sholehah diperoleh dari pernikahan yang sah. BSM mendukung karyawan untuk menikah sesuai syariat Islam dan memberikan ijin/ cuti bagi karyawan yang menikah. Hal ini diberikan sebagai wujud perhatian dan dukungan bahwa pernikahan yang sah sesuai dengan syariat Islam akan membawa keberkahan bagi kehidupan selanjutnya. Namun, BSM juga memunyai kebijakan bahwa dilarang menikahi teman sekantor dengan alasan mengurangi profesionalisme dalam bekerja. Hal ini diperbolehkan dalam Islam karena sudah disampaikan di dalam kontrak pekerjaan yang disetujui karyawan sebelum masuk di BSM. Kedua, selain cuti menikah, BSM juga memberikan cuti melahirkan kepada karyawan selama tiga bulan. Hal ini dilakukan untuk memberikan kesempatan bagi karyawan untuk bisa merawat anaknya dengan kasih sayang sebelum kembali pada aktivitasnya di kantor.

Ketiga, penerapan menjaga keturunan juga tercermin dalam adanya tunjangan kepegawaian yang meliputi tunjangan untuk keluarga termasuk anak. Hal ini dimaksudkan agar kehidupan keluarga karyawan lebih terjamin dari segi finansial. Dari asuransi kesehatan juga dijamin dengan adanya asuransi Inhealth yang mengcover seluruh kesehatan karyawan (karyawan wanita boleh menanggung kesehatan anak dan suami)

Keempat, perlindungan terhadap keturunan juga ditentukan berdasarkan keberlangsungan ekosistem lingkungan hidup. Oleh karena itu, BSM menggunakan material dan energi yang ramah lingkungan (kendaraan LCGC/
Low Cost Green Car) dengan bahan bakar yang disediakan pemerintah dan paperless untuk kegiatan operasionalnya. Selain itu, pengolahan limbah memang tidak dilakukan secara khusus mengingat limbah yang dihasilkan BSM tidak bersifat merusak alam, namun BSM tetap menerapkan prinsip 3R (Reuse, Reduce, dan Recycle) untuk penggunaan material maupun energi. Hal ini dilakukan sebagai bentuk komitmen BSM dalam keikutsertaannya menjaga kelestarian lingkungan hidup dan keharmonisan alam semesta demi anak dan keturunan selanjutnya.

\section{Implementasi Perlindungan terhadap Harta (Al-Maal)}

Perlindungan terhadap harta tercemin dalam: pertama, setiap produk yang ditawarkan oleh BSM. BSM berupaya menjaga dan mengalokasikan dananya dengan baik dan halal meskipun diperbolehkan mengambil profit yang wajar. Kedua, terlihat juga dari adanya penerapan sistem zakat yang bertujuan membersihkan harta nasabah secara transparan. Dana Zakat BSM berasal dari zakat perusahaan (dihitung dari laba BSM), nasabah umum (dana yang diterima dari nasabah), serta zakat pegawai (gaji, upah, bonus). LAZNAS BSM sebagai Lembaga amil zakat dari BSM selalu mematuhi ketentuan dan peraturan yang berlaku. Melalui program Mitra Umat, Didik Umat dan Simpati Umat, BSM dan LAZNAS menyalurkan dana zakat sesuai dengan delapan golongan aznaf penerima zakat.

Ketiga, pembagian laba dilakukan dengan prinsip bagi hasil. Maksudnya adalah dana yang disimpan/disalurkan akan dikelola sesuai dengan prinsip Syariah dan ketika memeroleh laba maka akan dibagikan sesuai dengan nisbah yang sudah disetujui dalam akad (dilakukan di awal transaksi) dan sesuai 
proporsi pengelolaan. Dengan cara seperti itu, pengelolaan keuangan BSM terhindar dari riba yang haram.

\section{KESIMPULAN}

Berdasarkan penjelasan dan buktibukti yang ditemukan dalam annual report BSM maka dapat disimpulkan bahwa BSM telah menerapkan 5 unsur maqasid Syariah yaitu perlindungan terhadap agama (alDien), perlindungan terhadap jiwa (al-
Nafs), perlindungan terhadap akal (alAql), perlindungan terhadap kehormatan dan keturunan, serta perlindungan terhadap harta (al-Maal) dalam setiap kegiatan yang dilakukan. [19]

Hal ini berarti bahwa sebagai mitra Universitas yang Islami, BSM telah sesuai dengan prinsip-prinsip Syariah dalam pengelolaannya dan layak untuk dipercaya, bukan hanya nama "Syariah" yang menempel saja.

\section{DAFTAR PUSTAKA}

[1] www.ojk.go.id, "No Title." .

[2] P. Said, I. Ahmad, and F. Javaid, Handbook of Islamic Banking Products E Services State Bank of Pakistan. Pakistan: Islamic Banking Department, State BAnk of Pakistan, 2008.

[3] N. Schoon, "Islamic Finance Product Explained," in Modern Islamic Banking: Product and processes in practice, John Wiley\&Sons Ltd., 2016, pp. 51-71.

[4] Isra, "Prinsip dan Operasi Pers," in Sistem Keuangan Islam, 2015.

[5] Sakirman, "Maqasid syariah Asy Syatibi," 2012.

[6] F. Djamil, "Sejarah, Teori, dan Konsep," in Hukum Ekonomi Islam, Jakarta: Sinar Grafika, 2013.

[7] Muthoifin, "Shariah hotel and mission religion in surakarta indonesia," Humanit. Soc. Sci. Rev., vol. 7, no. 4, pp. 973-979, 2019, doi: 10.18510/hssr.2019.74133.

[8] A. C. Fadilla Purwitasari, "Analisis PElaporan Corporate Social Responsibility Perbankan Syariah dan Perspektif Sharia Enterprise Theory," 2011.

[9] V. S. Dewi and Farida, “Maqasid Syariah," J. Ekon. Pembang. Optim., vol. 9, no. 1, pp. 73-84, 2019.

[10] B. P. Muthoifin, "Readiness Towards Halal Tourism in Indonesia Perspective of Reality and Religion," Int. J. Adv. Sci. Technol., vol. 29, no. 8, pp. 862-870, 2020.

[11] R. Kriantono, Teknik Praktis Riset Komunikasi. Jakarta: PT. Kencana Perdana, 2006.

[12] A. A. M. H. Jauhar, Maqasid Syariah. Jakarta: Amzah, 2013.

[13] A. Mingka, Maqasid Syariah dalam Ekonomi dan Keuangan Syariah. Jakarta: Ikatan Ahli Ekonomi Islam, 2013.

[14] S. shobron Muthoifin and S. A. Rahman, "Humanist islam in indonesia ahmad syafii maarif perspective," Humanit. Soc. Sci. Rev., vol. 7, no. 6, pp. 780-786, 2019, [Online]. Available: https://giapjournals.com/index.php/hssr/article/view/ hssr.2019.76118/2384.

[15] E. C. Syamsul Hidayat, Sudarno Shobron, Muthoifin, "Pancasila and Communism Perspectives on Islamic Thought," Int. J. Psicososial Rehabil., vol. 24, no. 8, pp. 3500-3508, 2020. 
[16] K. Hadi, "Implementasi Maqoshid Syariah Sebagai Indikator Perusahaan Islami," J. Al Azhar Indones. seri Pranata Sos., vol. 1, no. 3, pp. 140-150, 2012.

[17] R. Ali and Makhlani, "Pembangunan Ekonomi Dalam Tinjauan Maqashid Syariah," Dialog, vol. 36, no. 1, 2013.

[18] M. Zaki and B. T. Cahya, "Aplikasi Maqasid Asy-Syari'Ah Pada Sistem Keuangan Syariah," Bisnis, vol. 3, no. 2, pp. 312-327, 2015.

[19] M. Sudarno Shobron, Amrin, Imron Rosyadi, "Islamic Education Values in the Tradition of Peta Kapanca of Mbojo Community Tribe in West Nusa Tenggara," Int. J. Adv. Sci. Technol., vol. 29, no. 5, pp. 6802-6812, 2020. 